\title{
Gambaran Penangkapan Edukasi yang Diberikan kepada Pasien Hipertensi di Ruang Konsultasi Puskesmas Jatinangor
}

\author{
Helida Amalia Putri ${ }^{1}$, Yulia Sofiatin ${ }^{2}$, Rully M. A. Roesli ${ }^{3}$ \\ ${ }^{1}$ Fakultas Kedokteran, Universitas Padjadjaran, \\ ${ }^{2}$ Departemen Ilmu Kesehatan Masyarakat, Fakultas Kedokteran Universitas Padjadjaran, \\ ${ }^{3}$ Departemen Ilmu Penyakit Dalam, Fakultas Kedokteran Universitas Padjadjaran/Rumah Sakit Umum Pusat \\ Dr. Hasan Sadikin, Bandung, Indonesia
}

\begin{abstract}
Abstrak
Penelitian kualitatif terhadap pasien dan tenaga kesehatan di Jatinangor memperlihatkan bahwa proses penegakkan diagnosis dan penatalaksanaan hipertensi belum sesuai protokol, termasuk pemberian edukasi. Pemberian edukasi kepada pasien hipertensi penting dalam pengendalian tekanan darah. Edukasi kesehatan melibatkan dua pihak, tenaga kesehatan dan pasien. Sebelum materi edukasi dapat diterapkan, pasien harus merasa sudah menerima edukasi tersebut. Penelitian ini bertujuan mengetahui gambaran penangkapan edukasi yang diberikan kepada pasien hipertensi di ruang konsultasi Puskesmas Jatinangor. Suatu studi deskriptif kuantitatif, dilakukan dari Desember 2015 - Juli 2016 di Puskesmas Jatinangor. Responden adalah pasien yang berobat ke Balai Pengobatan Puskesmas Jatinangor dengan diagnosis hipertensi. Data yang dicari adalah kesesuaian pemberian dan penangkapan edukasi mengenai penegakkan diagnosis, modifikasi gaya hidup dan farmakologi antara tenaga kesehatan dan pasien hipertensi. Hasil penelitian menunjukkan edukasi penegakkan diagnosis berupa konfirmasi tekanan darah dan edukasi modifikasi gaya hidup berupa penurunan asupan garam merupakan edukasi yang paling banyak ditangkap oleh pasien, berturut-turut $(79 \%)$ dan $(34 \%)$. Lebih dari $(90 \%)$ pasien merasa tidak diberi edukasi farmakologi dan modifikasi gaya hidup lainnya. Simpulan penelitian ini adalah banyak pasien hipertensi yang tidak menerima edukasi mengenasi penegakkan diagnosis dan terapi untuk penyakitnya sehingga diperlukan sarana lain untuk memberikan edukasi di luar ruang konsultasi.
\end{abstract}

Kata Kunci: Hipertensi, Penangkapan edukasi, Puskesmas

\section{Patient Awareness on Hypertension Education Given at the Consultation Room of Public Health Center in Jatinangor}

\begin{abstract}
A prior qualitative study towards patients and health professional at Jatinangor showed that diagnosing and hypertension management are not follow the authorized protocol, specifically health education delivery. Patient education is essential for controlling blood pressure. Patients have to be aware that they received the information. This study is conducted to explore the extent of awareness on education given to the hypertensive patient at the consultation room of Public Health Center (Pusat Kesehatan Masyarakat, Puskesmas) in Jatinangor. A descriptive, quantitative study was conducted from December 2015 - July 2016 in Puskesmas Jatinangor. Respondents were patients visiting the clinic of Puskesmas Jatinangor and diagnosed with hypertension. Data regarding the conformity of delivery and acceptance of education about diagnosis establishment, lifestyle modification and pharmacology was collected. The result of this study showed that $79 \%$ and $34 \%$ of patients aware of the blood pressure confirmation and salt intake reduction as the most accepted education. More than $90 \%$ of the patient received none of pharmacological and other life style modification education. In conclusion, most of the hypertensive patients were not received education on diagnosis and management of their disease. Patient support group is a promising vehicle to deliver content of educations.
\end{abstract}

Keywords : Education acceptance, Hypertension, Public Health Center

Korespondensi:

Helida Amalia Putri

Fakultas Kedokteran, Universitas Padjadjaran

Jl. Raya Bandung-Sumedang km 21 Jatinangor

Mobile : 085223113114

Email : helidaamaliaputri@gmail.com 


\section{Pendahuluan}

Hipertensi merupakan penyakit tidak menular yang ditandai dengan adanya peningkatan tekanan darah secara kronis dan merupakan masalah kesehatan utama yang harus segera diatasi. ${ }^{1}$ Jika penyakit ini dibiarkan secara terusmenerus, fungsi organ-organ lain, terutama organ vital seperti jantung dan ginjal dapat terganggu. ${ }^{1}$ Menurut Riset Kesehatan Dasar (RISKESDAS) 2013, prevalensi hipertensi di Indonesia mencapai 26,5\%, sementara itu Provinsi Jawa Barat menempati angka prevalensi hipertensi tertinggi ketiga setelah Bangka Belitung dan Kalimantan Selatan, yaitu sebesar 29,4\%. ${ }^{1}$ Hal itu diperkuat dengan hasil survey pada tahun 2014 yang menyatakan bahwa Jatinangor yang merupakan salah satu kecamatan yang ada di Kabupaten Sumedang, Provinsi Jawa Barat memiliki prevalensi hipertensi yang lebih tinggi dibandingkan dengan angka nasional, yaitu sebesar $37,8 \%{ }^{2}$

Penderita penyakit kronis seperti hipertensi sangat sulit untuk patuh terhadap pengobatan yang diberikan. ${ }^{3}$ Berdasarkan data $\mathrm{WHO}$, hanya $50 \%$ pasien hipertensi yang berobat yang patuh terhadap pengobatannya, angka kepatuhan pasien di negara berkembang akan jauh lebih rendah, mengingat kurangnya tenaga kesehatan dan sulitnya akses terhadap pelayanan kesehatan. ${ }^{3} \mathrm{Di}$ Jatinangor, banyak pasien hipertensi yang tidak menyadari kondisi hipertensinya (36\%), dan $25 \%$ dari yang mengetahui dirinya hipertensi, tidak berobat. ${ }^{4}$ Sejalan dengan survei tersebut, dari penelitian kualitatif terhadap pasien hipertensi di Jatinangor terungkap bahwa proses penegakkan diagnosis dan tatalaksana hipertensi masih belum sesuai protokol. ${ }^{5}$

Kepatuhan pasien dalam menjalani terapi merupakan salah satu kunci tercapainya tekanan darah yang terkontrol pada pasien hipertensi. Kepatuhan pasien tersebut dipengaruhi oleh 5 dimensi yang saling terkait satu sama lain, yaitu faktor sosial dan ekonomi, faktor sistem pelayanan kesehatan, faktor kondisi penyakit, faktor terapi dan faktor pasien. ${ }^{3}$ Kelima dimensi tersebut sangat erat kaitannya dengan peran tenaga kesehatan dan pasien. Peran dari tenaga kesehatan tersebut meliputi penegakkan diagnosis, pemberian terapi serta edukasi farmakologi dan modifikasi gaya hidup mengenai rencana terapi yang akan dijalani oleh pasiennya. Di lain pihak, pasien membutuhkan saran, dukungan dan informasi dari tenaga kesehatan agar mereka menyadari betapa pentingnya mengontrol tekanan darahnya. ${ }^{3}$ Namun, meskipun penegakkan diagnosis, pemberian terapi dan edukasi yang diberikan oleh tenaga kesehatan sudah sangat baik sekalipun, belum tentu hal tersebut dapat ditangkap oleh pasien.

Selain pemberian edukasi, tenaga kesehatan harus memastikan bahwa pasien menangkap dan memahami isi edukasi tersebut. "The Stage Theory Model" karya Atkinson and Shiffrin, mengungkap bahwa proses pengolahan informasi terjadi secara bertahap dan terdiri dari tiga jenis atau tiga tahapan memori, yaitu memori sensorik, memori jangka pendek atau memori kerja dan memori jangka panjang. Berdasarkan teori ini proses pembelajaran dan daya ingat tidak saling berlanjut dan terjadi secara bertahap. Hal itu diperkirakan ketika terdapat informasi baru, informasi tersebut akan ditangkap terlebih dahulu yang selanjutnya akan dilakukan manipulasi sebelum informasi tersebut disimpan. ${ }^{6}$ Oleh karena itu, penelitian ini bertujuan untuk mengetahui gambaran penangkapan edukasi yang diberikan kepada pasien hipertensi di ruang konsultasi Puskesmas Jatinangor, mengingat bahwa penangkapan edukasi yang baik oleh pasien erat kaitannya dalam proses meningkatkan kepatuhan pasien dalam menjalani terapi.

\section{Metode}

Penelitian dilakukan dari bulan Desember 2015 sampai Juli 2016 di Puskesmas Jatinangor, menggunakan studi desain deskriptif kuantitatif. Populasi pada penelitian ini adalah pasien yang berobat di Balai Pengobatan Puskesmas Jatinangor. Subjek dipilih dengan menggunakan metode consecutive sampling, yaitu pasien yang datang berobat untuk hipertensi atau memiliki tekanan darah yang tinggi saat peneliti berada di Puskesmas Jatinangor.

Kriteria inklusi pada penelitian ini adalah pasien yang datang berobat dan memiliki tekanan darah yang tinggi saat peneliti berada di Puskesmas Jatinangor serta menyatakan kesediaannya untuk berpartisipasi dalam penelitian ini dengan menandatangani lembar persetujuan setelah penjelasan (informed-consent).

Sedangkan kriteria eksklusinya adalah pasien hipertensi yang datang berobat ke Puskesmas Jatinangor $>4$ kali. Jumlah minimal sampel yang dibutuhkan pada penelitian ini sebanyak 97 yang ditentukan berdasarkan rumus penelitian deskriptif kategorik untuk menaksir proporsi populasi. Data yang diambil merupakan data sekunder daripenelitian sebelumnyayang berjudul "Pencegahan Primer dan Sekunder terhadap Hipertensi pada Masyarakat Jatinangor", dengan nomor etik 589/UN6.C1.3.2/KEPK/ $\mathrm{PN} / 2015$. Oleh karena itu, sebelum penelitian ini dilakukan sudah mendapatkan persetujuan 
dari Komisi Etik Penelitian Kesehatan. Data yang dikumpulkan adalah data dari Formulir observasi tenaga kesehatan mengenai pemberian edukasi hipertensi kepada pasien saat di ruang pemeriksaan. Formulir diisi oleh surveyor di ruang pemeriksaan dan Kuesioner tentang penangkapan edukasi hipertensi yang diberikan kepada pasien saat di ruang pemeriksaan. Kuesioner diisi dengan mewawancarai pasien hipertensi setelah keluar dari ruang pemeriksaan.

Pengambilan data dari kuesioner tersebut disesuaikan dengan variabel penelitian yang akan diteliti, terdiri dari edukasi penegakkan diagnosis meliputi konfirmasi prosedur pemeriksaan, konfirmasi faktor risiko, dan konfirmasi penyulit; edukasi modifikasi gaya hidup, meliputi penurunan berat badan, penurunan asupan garam, olahraga dan aktivitas fisik, rujuk ke ahli gizi, pengendalian stress dan edukasi penyakit lain yang diderita oleh pasien; serta edukasi farmakologi, meliputi nama obat, dosis, manfaat, efek samping dan kesinambungan pengobatan obat antihipertensi. Setelah data terkumpul, selanjutnya dilakukan proses pengolahan data dan disajikan dalam bentuk tabel dan grafik untuk menggambarkan gambaran penangkapan edukasi yang diberikan kepada pasien hipertensi di ruang konsultasi Puskesmas Jatinangor. Yang dimaksud dengan penangkapan dalam penelitian ini terbatas pada kesadaran pasien bahwa tenaga kesehatan memberikan beberapa aspek edukasi. Pada penelitian ini belum sampai pada tahap untuk mengetahui gambaran pemahaman pasien.

\section{Hasil}

Berdasarkan penelitian yang dilakukan diperoleh jumlah sampel yang memenuhi kriteria pada penelitian ini sebanyak 100 orang.Dari seluruh subjek penelitian, subjek berjenis kelamin perempuan lebih banyak dibandingkan laki-laki. Rentang usia dari penelitian ini dimulai dari usia $\geq 26$ tahun dan paling banyak berada di rentang usia 46-55 tahun. Dari 100 pasien yang menjadi subjek penelitian didapatkan median tekanan darah sistolik pasien $150 \mathrm{mmHg}$, sedangkan median tekanan darah diastoliknya $90 \mathrm{mmHg}$.

Tabel 1 Data Dasar Pasien Hipertensi

\begin{tabular}{cc}
\hline Kategori & Jumlah(n=100) \\
\hline Jenis Kelamin: & \\
Laki-laki & 32 \\
Perempuan & 68 \\
Usia: &
\end{tabular}

\begin{tabular}{lc} 
26-35 tahun & 5 \\
$36-45$ tahun & 25 \\
$46-55$ tahun & 30 \\
56-65 tahun & 22 \\
$>65$ tahun & 16 \\
Data tidak lengkap & 2 \\
\hline Median (Min-Max) & \\
Tekanan Darah: & $150(130-250)$ \\
Sistolik & $90(80-120)$ \\
Diastolik &
\end{tabular}

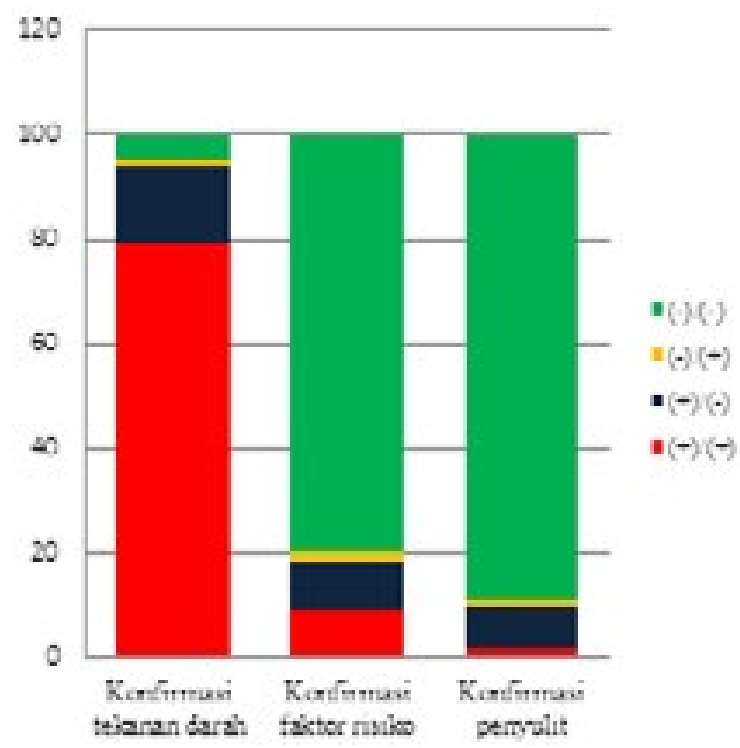

Gambar 1 Distribusi Penangkapan Edukasi Keterangan: Penegakkan Diagnosis

$(+) /(+)=$ Tenaga kesehatan memberikan edukasi dan pasien menangkap edukasi tersebut

$(+) /(-)=$ Tenaga kesehatan memberikan edukasi, namun pasien tidak menangkap edukasi tersebut' $(-) /(+)=$ Tenaga kesehatan tidak memberikan edukasi, namun pasien mengetahui edukasi tersebut

$(-) /(-)=$ Tenaga kesehatan tidak memberikan edukasi sehingga pasien tidak menangkap edukasi tersebut.

Grafik 1 menunjukkan distribusi penangkapan edukasi penegakkan diagnosis. Dari edukasi penegakkan diagnosis, konfirmasi tekanan darah merupakan salah satu edukasi yang paling banyak diberikan oleh tenaga kesehatan di Puskesmas. Sebesar 79\% pasien yang menangkap edukasi konfirmasi tekanan darah dan hanya $15 \%$ pasien yang tidak menangkap edukasi tersebut. Sebaliknya, untuk konfirmasi faktor risiko dan penyulit, berturut-turut $89 \%$ 
dan $97 \%$ pasien merasa bahwa tenaga kesehatan tidak memberikan edukasi tersebut, dan memang sebagian besar tidak dilakukan konfirmasi faktor risiko dan penyulit.

Grafik 2 menunjukkan distribusi penangkapan edukasi modifikasi gaya hidup. Dari edukasi modifikasi gaya hidup, edukasi penurunan asupan garam merupakan edukasi yang paling banyak ditangkap oleh pasien, sebesar 34\%. Terdapat $12 \%$ pasien yang mengetahui edukasi tersebut tanpa diberitahu terlebih dahulu oleh tenaga kesehatan. Sisanya, lebih dari $90 \%$ pasien menyatakan tidak diberi edukasi modifikasi gaya hidup lainnya, seperti penurunan berat badan, olahraga dan aktivitas fisik, edukasi untuk dirujuk ke ahli gizi, pengendalian stress serta edukasi untuk penyakit lainnya yang diderita oleh pasien.

Grafik 3 menunjukkan distribusi penangkapan edukasi farmakologi. Dari 100 subjek penelitian, sangat sedikit pasien yang merasa dirinya diberikan edukasi farmakologi oleh tenaga kesehatan, khususnya mengenai edukasi efek samping dan kesinambungan pengobatan. Hanya $3 \%$ pasien yang merasa dirinya mengetahui efek samping obat yang diresepkan dan $1 \%$ yang mengetahui mengenai kesinambungan pengobatan obat antihipertensi yang akan dikonsumsinya. Selebihnya, pasien merasa bahwa tenaga kesehatan tidak memberikan edukasi farmakologi berupa nama obat, dosis, manfaat, efek samping dan kesinambungan pengobatan mengenai obat-obatan yang diresepkan padanya.

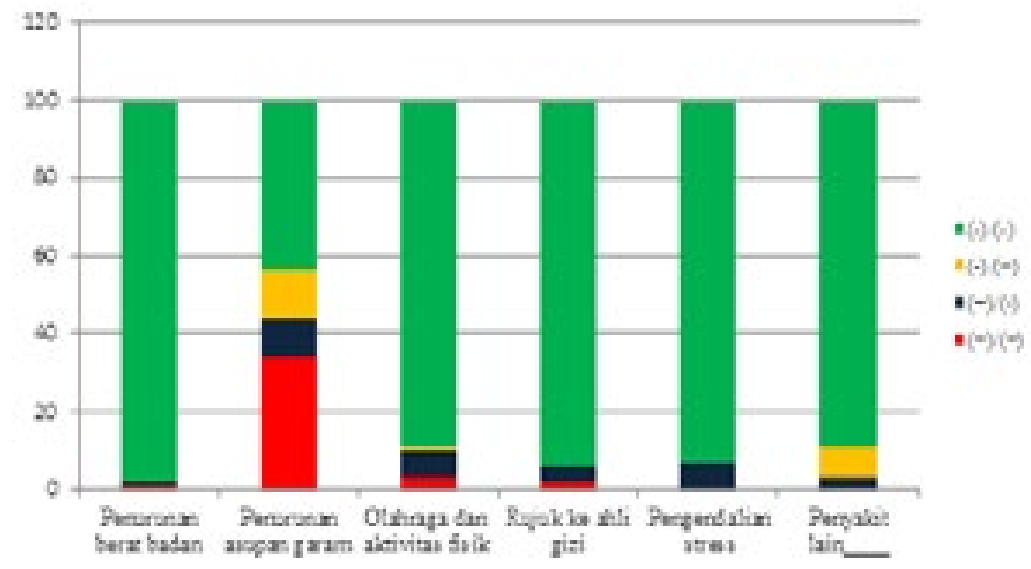

Keterangan:

\section{Gambar 2 Distribusi Penangkapan Edukasi Modifikasi Gaya Hidup}

$(+) /(+)=$ Tenaga kesehatan memberikan edukasi dan pasien menangkap edukasi tersebut

$(+) /(-)=$ Tenaga kesehatan memberikan edukasi, namun pasien tidak menangkap edukasi tersebut

$(-) /(+)=$ Tenaga kesehatan tidak memberikan edukasi, namun pasien mengetahui edukasi tersebut

$(-) /(-)=$ Tenaga kesehatan tidak memberikan edukasi sehingga pasien tidak menangkap edukasi tersebut

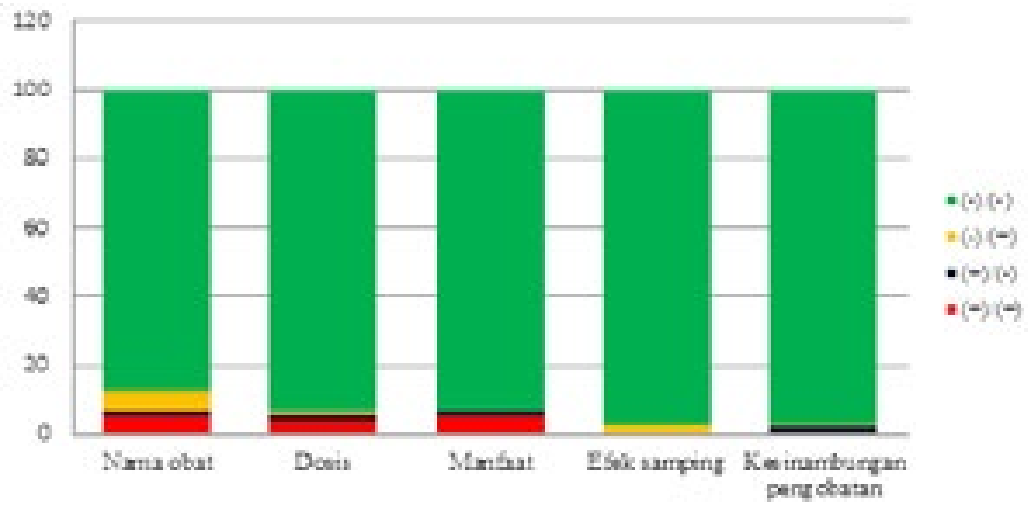

Keterangan:

Gambar 3 Distribusi Penangkapan Edukasi Farmakologi

$(+) /(+)=$ Tenaga kesehatan memberikan edukasi dan pasien menangkap edukasi tersebut

$(+) /(-)=$ Tenaga kesehatan memberikan edukasi, namun pasien tidak menangkap edukasi tersebut

$(-) /(+)=$ Tenaga kesehatan tidak memberikan edukasi, namun pasien mengetahui edukasi tersebut

$(-) /(-)=$ Tenaga kesehatan tidak memberikan edukasi sehingga pasien tidak menangkap edukasi tersebut 


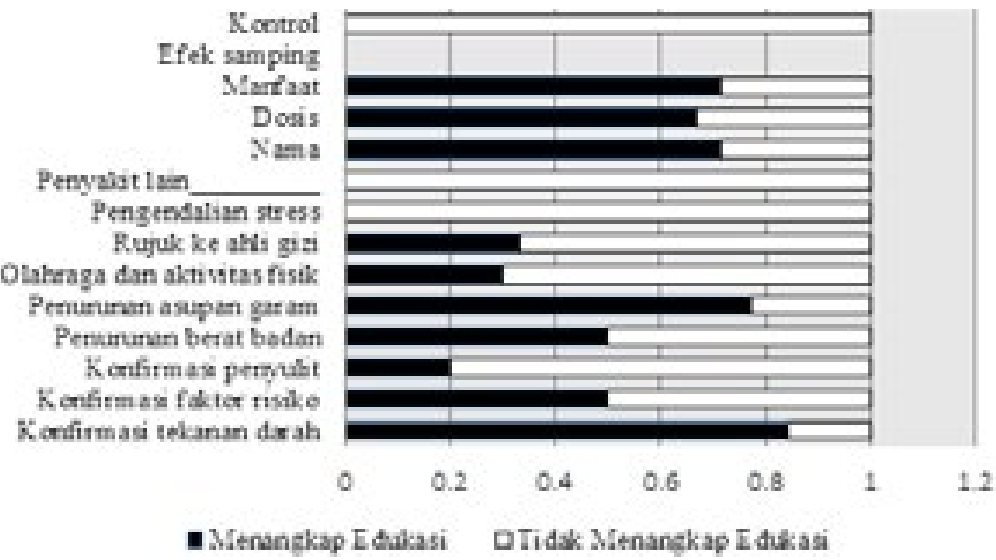

\section{Gambar 4 Distribusi Penangkapan Edukasi Hipertensi yang Diberikan oleh Tenaga Kesehatan}

Grafik 4 menunjukkan distribusi penangkapan edukasi hipertensi yang diberikan oleh tenaga kesehatan. Sebagian besar, lebih dari 5/10 proporsi pasien menangkap edukasi yang diberikan oleh tenaga kesehatan. Jika dilihat dari grafik ini, edukasi penegakkan diagnosis, modifikasi gaya hidup dan edukasi mengenai obat, bila diberikan oleh tenaga kesehatan, ditangkap dengan baik oleh pasien.

\section{Pembahasan}

Pada penelitian ini jumlah subjek perempuan yang datang ke Balai Pengobatan Puskesmas Jatinangor dengan penyakit hipertensi lebih banyak dibandingkan laki-laki. Hal ini sesuai dengan penelitian Faris, dkk. yang menunjukkan bahwa jumlah penderita hipertensi di Jatinangor lebih banyak pada perempuan. Distribusi jenis kelamin pada penduduk Jatinangor tidak merata, hal ini dikarenakan banyak laki-laki masyarakat Jatinangor yang bekerja di luar kota. $^{2}$ Selain itu, jumlah pasien hipertensi yang berobat ke puskesmas Jatinangor paling banyak berada di rentang usia 46-55 tahun padahal menurut penelitian sebelumnya mengungkap bahwa prevalensi hipertensi paling banyak berada di usia lebih dari 60 tahun. ${ }^{2}$ Hal ini diperkirakan bahwa pasien usia lanjut sulit untuk menjangkau pelayanan kesehatan karena mobilitas yang menurun dan akses yang sulit. Kenyataan ini menunjukkan kebutuhan untuk mendekatkan sarana edukasi kepada kelompok ini. Tujuan diberikannya edukasi dan dukungan kepada pasien adalah untuk meningkatkan kepatuhan pasien dalam menjalani terapi sebagai pencegahan sekunder hipertensi. ${ }^{3}$ Di Jatinangor sendiri, prevalensi komplikasi yang disebabkan oleh hipertensi mencapai 33,9\%. Komplikasi hipertensi yang umumnya diderita masyarakat Jatinangor adalah serangan jantung dan stroke. ${ }^{2}$ Banyak pasien hipertensi yang tidak menyadari kondisi hipertensinya (36\%), dan $25 \%$ dari yang mengetahui dirinya hipertensi, tidak berobat, faktor-faktor ini dapat merupakan faktor risiko tingginya komplikasi di Jatinangor. ${ }^{4}$ Selain itu, penelitian sebelumnya juga menunjukkan, terdapat kegagalan pengendalian tekanan darah pada pasien yang minum obatnya sudah tepat. ${ }^{7}$ Dari penelitian-penelitian tersebut dapat disimpulkan, meskipun diagnosis dan pemilihan obat oleh tenaga kesehatannya sudah benar, hal itu belum cukup menjamin keberhasilan suatu terapi jika tidak diimbangi dengan kepatuhan pasien dalam melakukan perubahan gaya hidup dan mengonsumsi obatnya. ${ }^{8}$ Kepatuhan pasien dapat meningkat jika pasien mengetahui beratnya penyakit. ${ }^{9}$ Hal ini akan memberikan dampak positif terhadap kepatuhan jika pasien merasa penyakit yang dideritanya sangat memerlukan pengobatan yang lebih serius. ${ }^{3}$ Penelitian di USA juga menunjukkan, pasien yang memiliki status kesehatan yang buruk akan lebih patuh terhadap terapi. ${ }^{10}$ Oleh karena itu, edukasi mengenai tekanan darah, faktor risiko hipertensi dan penyulit menjadi penting untuk disampaikan kepada pasien. ${ }^{3,9}$

Menurut protokol pengendalian tekanan darah, edukasi penegakkan diagnosis terdiri dari konfirmasi tekanan darah, faktor risiko hipertensi dan penyulit. Pada penelitian ini, konfirmasi tekanan darah merupakan edukasi yang paling banyak ditangkap oleh pasien. Banyak pasien merasa bahwa tenaga kesehatan di Puskesmas tidak memberikan edukasi penegakkan diagnosis, khususnya mengenai konfirmasi faktor risiko dan penyulit. Dampak yang mungkin timbul dari 
ketidaktahuan pasien terhadap beratnya diagnosis ini adalah rendahnya kesadaran pasien terhadap penyakit yang dideritanya.

Sebagian besar tekanan darah tinggi tidak dapat diobati, namun masih dapat dikendalikan dengan cara melakukan modifikasi gaya hidup, dan jika dibutuhkan dapat dikendalikan dengan mengonsumsi obat antihipertensi. ${ }^{11}$ Menurut protokol pengendalian tekanan darah, modifikasi gaya hidup dapat membantu menurunkan tekanan darah, mencegah atau menunda angka kejadian hipertensi, meningkatkan efficacy obat antihipertensi serta menurunkan risiko terkena penyakit kardiovaskular. ${ }^{12}$ Selain dapat menurunkan tekanan darah, manfaat lain dari modifikasi gaya hidup ini tentunya lebih murah dan lebih mudah dijangkau oleh pasien. ${ }^{11}$

Penurunan berat badan sekitar $4,5 \mathrm{~kg}$ terbukti dapat menurunkan tekanan darah dan/ atau mencegah hipertensi pada seseorang yang mengalami overweight. Selain itu, penurunan tekanan darah juga dapat dilakukan dengan menerapkan Dietary Approaches to Stop Hypertension (DASH) yang meliputi diet kaya akan buah, sayur, lowfat dairy products, rendah kolesterol dan rendah lemak jenuh maupun lemak total. Diet yang dianjurkan juga meliputi diet tinggi kalium dan kalsium, serta rendah natrium $(<100 \mathrm{mmol}$ atau setara dengan 2,4 gram per hari). Bagi pasien yang mampu melakukan olahraga aerobik, dianjurkan untuk melakukan aktivitas fisik berupa jalan cepat sekurangkurangnya 30 menit beberapa hari dalam setiap minggunya. Selain itu, gaya hidup yang tidak baik seperti meminum alkohol dan merokok sebaiknya dihindari. Kombinasi dua atau lebih modifikasi gaya hidup ini dapat memberikan hasil yang lebih baik. ${ }^{12}$

Untuk meningkatkan kepatuhan pasien dalam menjalani modifikasi gaya hidup diperlukan pemberian edukasi yang cukup efektif kepada pasien hipertensi. ${ }^{13}$ Dalam penelitian ini mengungkap bahwa hanya $34 \%$ pasien yang merasa diberi edukasi penurunan asupan garam, ada $12 \%$ pasien yang merasa mendapat edukasi ini tanpa diberitahu terlebih dahulu oleh tenaga kesehatan (diperkirakan pasien ini mendapatkan sumber informasi dari tempat lain). Dari 100 subjek penelitian, tidak ada satupun pasien yang merasa bahwa dirinya mendapatkan edukasi mengenai pengendalian stress. Padahal, penelitian lain menyebutkan bahwa stress yang bersifat kronis seperti stress terhadap pekerjaan dan lingkungan sosial serta rendahnya status sosial dan ekonomi seseorang dapat meningkatkan risiko terkena penyakit hipertensi. ${ }^{14}$ Sementara itu, lebih dari $90 \%$ pasien merasa tidak diberi edukasi modifikasi gaya hidup lainnya, seperti penurunan berat badan, olahraga serta edukasi untuk konsultasi ke ahli gizi. Hal ini sesuai dengan penelitian Nazmun, dkk. yang mengungkap bahwa modifikasi gaya hidup belum dipahami betul oleh penderita hipertensi di Jatinangor. ${ }^{5}$

Jika terapi nonfarmakologi tidak dapat mengendalikan tekanan darah, tenaga kesehatan dapat mulai meresepkan obat antihipertensi sesuai dengan derajat hipertensi pasiennya. Tujuan dari terapi antihipertensi adalah untuk menurunkan morbiditas dan mortalitas dari penyakit kardiovaskular dan ginjal. Terapi antihipertensi juga dapat menurunkan risiko stroke dan infark miokardium sebesar 35-40 persen dan 20-25 persen, serta gagal jantung $>50$ persen. ${ }^{12}$

Dalam pengobatan antihipertensi, pasien memerlukan arahan, dukungan dan informasi dari tenaga kesehatan dalam hal mengetahui kepentingan mengontrol tekanan darah, menggunakan obat secara rasional, bagaimana menangani dosis yang terlewatkan serta bagaimana mengidentifikasi adanya efek samping dari obat yang dikonsumsi. Hal tersebut sangat penting diketahui pasien karena berkaitan erat dengan kepatuhan pasien dalam menjalani pengobatan. ${ }^{3}$

Dari hasil penelitian ini didapatkan lebih dari $90 \%$ pasien merasa tidak mendapat edukasi mengenai nama obat, dosis, manfaat, efek samping dan kesinambungan pengobatan obat antihipertensi yang akan dikonsumsinya. Dampak yang mungkin timbul dari ketidaktahuan pasien mengenai hal tersebut adalah pasien akan merasa tidak begitu peduli terhadap pengobatan yang akan ia jalani serta pengobatan tersebut tidak dijalankan secara teratur dan berkesinambungan. Hal ini sesuai dengan penelitian Ridwan, dkk. yang mengungkap bahwa sedikit sekali pasien yang berobat secara teratur. ${ }^{7}$

Khusus dalam hal edukasi mengenai obat, ada pemegang peranan lain, yaitu petugas apotek, yang juga mempunyai kewajiban untuk memberikan edukasi tentang obat pada saat pemberian obat. Sayangnya, menurut penelitian Ivan dkk. yang belum dipublikasikan, waktu pelayanan di tempat pemberian obat juga sangat singkat. ${ }^{15}$

Sedikitnya edukasi yang diberikan oleh tenaga kesehatan kepada pasien hipertensi di Puskesmas Jatinangor tampaknya terkait dengan waktu konsultasi yang singkat akibat jumlah pasien yang berobat terlalu banyak (dilaporkan dalam laporan lain). ${ }^{5}$

Keterbatasan dari penelitian ini diantaranya konten aspek edukasi yang diberikan oleh tenaga kesehatan tidak turut dievaluasi, yang dilihat pada penelitian ini hanya apakah edukasi tersebut ditangkap atau tidak oleh pasien. 
Dari penelitian ini dapat disimpulkan bahwa secara umum edukasi yang diterima pasien hipertensi di Puskesmas Jatinangor sangat kurang. Selain itu, edukasi hipertensi berupa penegakkan diagnosis, modifikasi gaya hidup dan edukasi obat, bila diberikan oleh tenaga kesehatan dapat ditangkap oleh pasien.

Kondisi Puskesmas Jatinangor tidak jauh berbeda dengan di Puskesmas lainnya sehingga hasil penelitian ini dapat menjadi cerminan pelayanan terhadap pasien hipertensi atau penyakit kronis lain di sebagian besar Puskesmas di Indonesia. ${ }^{15}$ Hasil penelitian ini memperlihatkan bahwa edukasi di ruang konsultasi tidak cukup, sehingga perlu upaya untuk pemberian edukasi kepada pasien hipertensi di luar ruang konsultasi. PROLANIS (Program Pengelolaan Penyakit Kronis) yang dicanangkan oleh Kementrian Kesehatan harus dievaluasi lebih lanjut agar sarana ini dapat berjalan lebih efektif dalam memberikan edukasi kepada pasien di luar ruang konsultasi.

\section{Daftar Pustaka}

1. Departemen Kesehatan Republik Indonesia. Riset Kesehatan Dasar (RISKESDAS) 2013. Jakarta: Badan Penelitian dan Pengembangan Kesehatan Kementerian Kesehatan, Republik Indonesia; 2013.

2. Fihaya FY, Sofiatin Y, Ong PA, Sukandar $\mathrm{H}$, Roesli RMA. Prevalence of hypertension and its complications in Jatinangor 2014. J Hypertens. 2015;33:35.

3. World Health Organization. Adherence to long-term therapies. Geneva: WHO; 2003.

4. Hamzah NKA, Roesli RMA, Sofiatin Y, Sukandar H. Awareness, treatment and control of hypertension in Jatinangor subdistrict between March-November 2014. J Hypertens. 2015;33:34-5.

5. Sofiatin Y, Laila N, Sitorus TD, Roesli RM. Office-setting education is not effective in modifying life-style of hypertensive patients in Indonesia. J Hypertens. 2016;34:12.

6. Ogmen H, Herzog M. Anew conceptualization of human visual sensory-memory. Front Psychol. 2016;7(830):1-15.

7. Putra MRD, Sofiatin Y, Hidayat EM, Sukandar H, Roesli RMA. Correlation between the correct use of drug and the achievement of blood pressure control. J Hypertens. 2015;33:35.

8. Asti TI. Kepatuhan pasien : Faktor penting dalam keberhasilan terapi. InfoPOM-Badan POM RI. 2006;7(5):1-12.

9. Mancia G, Fagard R, Narkiewicz K, Redon J, Zanchetti A, Bohm M, dkk. 2013 ESH/ ESC guidelines for the management of arterial hypertension: The Task Force for the management of arterial hypertension of the European Society of Hypertension (ESH) and of the European Society of Cardiology (ESC). Eur Heart J. 2013;34(28):2159-219.

10. Jin J, Sklar GE, Min V, Oh S. Factors affecting therapeutic compliance: A review from the patient' $\mathrm{s}$ perspective. Orig Res. 2008;4(1):269-86.

11. Nicoll R, Henein MY. Hypertension and lifestyle modification: How useful are the guidelines? $\mathrm{Br} \mathrm{J}$ Gen Pract. 2010;60(581):879-80.

12. Joint National Committe. The Seventh report of the Joint National Committee on prevention, detection, evaluation, and treatment of high blood pressure. New York: $\mathrm{NIH} ; 2004$.

13. Beigi MAB, Zibaeenezhad MJ, Aghasadeghi K, Jokar A, Shekarforoush S, Khazraei $\mathrm{H}$. The effect of educational programs on hypertension management. Int Cardiovasc Res J. 2014;8(3):94-8.

14. Spruill T. Chronic psychological stress and hypertension. Curr Hypertens Rep. 2013;12(1):10-6.

15. Pradipta IS, Alfian SD, Destiani DP. Monitoring dan Evaluasi Penggunaan Obat di Fasilitas Kesehatan Primer: Studi observasional untuk meningkatkan rasionalitas penggunaan dan biaya obat antihipertensi. Personal Communication. 2015;23. 